\title{
ENTREVISTA
}

\section{Formação profissional e certificação}

Nesta edição, a assessora técnica da Gerência de Prospecção e Avaliação Educacional do Departamento Nacional do Senac, Natalia Navarro, conversa com o professor Tomás Dias Sant'Anna, secretário de Educação Profissional e Tecnológica (SETEC) do Ministério da Educação (MEC). O fio condutor da entrevista foi a relação entre formação profissional e certificação de trabalhadores, assim como a requalificação dos mesmos, abordando programas como a Plataforma Monitor das Profissões e o Sistema Nacional de Reconhecimento e Certificação de Saberes e Competências Profissionais (Re-Saber), recém-lançados pelo MEC.

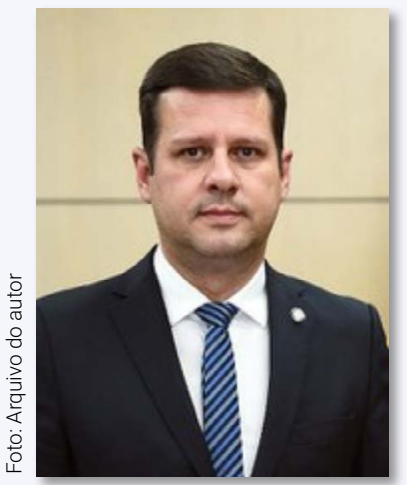

Tomás Sant'Anna Doutorando em Administração na Universidade de Brasília, mestre em Ciência da Computação pela Universidade de São Paulo e graduado em Ciência da Computação pela Universidade José do Rosário Vellano, Tomás Sant'Anna é professor da Universidade Federal de Lavras. De 2010 a 2018, atuou como próreitor de Planejamento, Orçamento e Desenvolvimento Institucional da Universidade Federal de Alfenas. Também foi, entre 2013 e 2017, coordenador nacional do Fórum de Pró-Reitores de Planejamento e Administração das Instituições Federais de Ensino Superior.

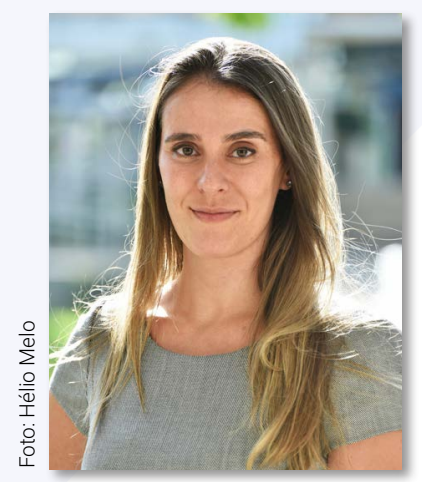

Natalia Navarro Cientista Social, mestre e doutora em administração pública e governo, com doutorado sanduíche na University of Oxford. Atualmente, é assessora técnica da Gerência de Prospecção e Avaliação Educacional do Departamento Nacional do Senac, construída uma trajetória de dez anos na educação profissional e tecnológica, tendo atuado como professora, coordenadora de curso e pesquisadora no Centro Universitário Senac de São Paulo. Conta com uma vasta experiência em pesquisa, com passagem por centros de excelência, como Centro de Estudos e Pesquisas em Administração Pública e Governo da Fundação Getúlio Vargas de São Paulo (CEAPG, FGV-SP) e o Latin American Centre da University of Oxford (LAC). 
NN - Sabe-se que a certificação a partir do reconhecimento de saberes e competências já é realizada em outros países, cada qual com as suas particularidades, para atender suas respectivas questões sociais e econômicas. Apesar disso, há uma discussão comum entre eles, centrada na superação da dicotomia formação/certificação profissional. Admitir que a educação formal não é a única via de profissionalização não significa, necessariamente, deixar de reconhecer a importância do investimento em políticas públicas de formação profissional e técnica. Nesse sentido, qual a proposta do MEC para combinar os esforços tanto na certificação profissional, para o reconhecimento social, quanto no aproveitamento de conhecimentos práticos, para a elevação da escolaridade e da progressão profissional?

TS - Com fundamento no que estabelece o artigo 41 da Lei no 9.394, de 20 de dezembro de 1996, Lei de diretrizes e Bases da Educação Nacional - LDB, o Ministério da Educação, por meio da Secretaria de Educação Profissional e Tecnológica (Setec), instituiu o Sistema Nacional de Reconhecimento e Certificação de Saberes e Competências Profissionais - Re-Saber, como um processo educativo, isto é, desenvolvido por instituições de educação profissional para certificar competências laborais de cidadãos maiores de 18 anos relacionadas às competências escolares dos cursos regulares. O reconhecimento social dos certificados e diplomas do Re-Saber são diretamente equivalentes aos mesmos documentos emitidos na conclusão de cursos regulares nas escolas técnicas, permitindo que o trabalhador possa retornar à escola e continuar ou concluir seus estudos, ressaltando que o Sistema não exclui a contínua oferta de cursos formais regulares para a qualificação e requalificação de cidadãos e trabalhadores.

NN - O senhor poderia nos contar qual a metodologia utilizada para a análise desses saberes e competências para reconhecimento da habilitação do trabalhador em determinada ocupação? E quais vantagens o Sistema apresenta em relação à Rede Certific?

TS - Os saberes e competências adquiridos ao longo da vida e do trabalho serão certificáveis apenas se mantiverem correlação direta com os saberes e competências desenvolvidos em cursos formais da educação profissional. A metodologia de análise, avaliação e certificação será indicada no Projeto Pedagógico de Certificação Profissional (PPCP), construído pelos professores de um curso de referência para a certificação e aprovado pelas instâncias próprias da instituição de ensino.

As vantagens em relação à Rede Certific se relacionam especialmente à simplificação burocrática do processo de certificação de saberes e competências, que deixa de ser uma rede para se tornar um sistema com funcionalidades incorporadas no Sistema Nacional de Informações da Educação Profissional e Tecnológica (Sistec).

NN - Sabemos que a velocidade com que as transformações na economia impactam a prática profissional é cada vez maior, o que, consequentemente, modifica os saberes exigidos para o reconhecimento da habilitação do trabalhador em determinada ocupação. De que modo a metodologia proposta pelo Re-Saber atenta para 
essas mudanças e para a atualização dos saberes para obtenção de certificação em uma ocupação?

TS - O Re-Saber orienta as instituições para que a construção do PPCP promova a avaliação das competências laborais próprias de cada profissão ou ocupação. Para os cursos de qualificação, devem ser observados os descritivos da Classificação Brasileira de Ocupações (СBO); para os cursos técnicos, o Catálogo Nacional de Cursos Técnicos (CNCT); e para os cursos de graduação tecnológica, o respectivo Catálogo Nacional de Cursos Superiores de Tecnologia (CNCST). Esses documentos são construídos e atualizados de acordo com a oferta educativa e as atividades laborais associadas. Desse modo, garante-se coerência entre a formação regular, a certificação de competências e o mundo do trabalho ao qual a certificação está associada.

NN - Diante do cenário de instabilidade econômica, o alto índice de desemprego se tornou motivo de grande preocupação no Brasil. E vale salientar a relevância da formação profissional como forma de incrementar a empregabilidade dos trabaIhadores, em um contexto de maior competitividade e de constantes e rápidas mudanças no mercado de trabalho. Nessa perspectiva, como o Sistema Nacional de Reconhecimento e Certificação de Saberes e Competências Profissionais contribui para melhorar a empregabilidade dos trabalhadores?

TS - O Re-Saber visa contribuir para o reconhecimento e certificação escolar de trabalhadores em seus respectivos campos de atividade. Conforme dados da PNAD/IBGE, a certificação profissional aumenta a laboralidade do trabalhador e suas chances de inserção no setor produtivo. Um certificado emitido por escola técnica, de qualquer sistema, tem reconhecimento social e econômico no Brasil. Assim, a certificação aumenta em grande medida as chances de emprego ou de ascensão laboral.

NN - 0 processo de avaliação intrínseco à certificação profissional gera um rico diagnóstico sobre as deficiências de aprendizagem em ocupações. Como as instituições de educação profissional poderão se apropriar dessas informações para o desenvolvimento de novos produtos educacionais ou mesmo para o aprimoramento de suas ofertas? De que forma as instituições educacionais serão integradas aos resultados do Re-Saber? O governo garantirá aos trabalhadores acesso à formação complementar nas competências em que eles se mostrarem deficientes?

TS - Um dos importantes objetivos do Sistema Re-Saber é provocar nas instituições de educação profissional o vínculo com o setor produtivo na proposição e implementação de processos de certificação profissional: em primeiro lugar, por realizar busca ativa de trabalhadores para seus processos de certificação e, em segundo lugar, atualizar seus projetos pedagógicos de curso a partir da análise da atividade laboral desenvolvida durante a construção do PPCP. É importante lembrar que o Re-Saber é, também, um processo educativo que permite às instituições identificar as lacunas nos conhecimentos e competências adquiridos para suplementá-los pela oferta de formações complementares. Essa é uma orientação que permeia todos os processos de certificação do Sistema Re-Saber. 
NN - No campo da educação formal, observa-se a passagem de um ensino centrado nos saberes disciplinares para um ensino definido para produzir competências verificáveis. Na mesma linha, o debate atual sobre certificação profissional também se concentra nas competências e nos conhecimentos tácitos aplicados ao exercício das atividades de uma ocupação no mercado de trabalho. No entanto, essa visão tem sido alvo de críticas por diversos estudiosos, que argumentam acerca dos riscos de olhar para a certificação profissional apenas pela ótica das competências específicas, subordinadas ao exercício de uma única ocupação, sem considerar a complexidade formativa da educação formal. Qual sua visão a respeito desse embate entre a necessidade de um sistema de certificação de um lado e o que deve ser objeto de certificação profissional de outro?

TS - A educação por competência é um movimento educacional mundial, que busca superar a educação por conteúdos, que é nosso modelo formal de educação. Além dos conteúdos, uma competência inclui os fazeres a ela associados e os valores socialmente consolidados dentro de nossa cultura. Dessa forma, a construção de uma competência é muito mais abrangente e humanizadora do que o modelo de educação por conteúdo. A intenção do Re-Saber é evidenciar para a escola que saberes vão além de conhecimentos formais, que competência é uma capacidade individual de articular conhecimentos, ações e valores adquiridos por meio das diversas interrelações que o cidadão estabelece durante a vida, em processos formais ou não, para a solução de uma situação ou problema.

NN - O reconhecimento/validação das qualificações constitui um dos grandes desafios a serem enfrentados na construção de um sistema de classificação das ocupações e de certificação profissional. Isso porque a validação da experiência profissional e das ações de formação deve obter seu reconhecimento não apenas entre os trabalhadores, mas entre empregadores. Na sua opinião, quais ações são necessárias para a construção coletiva de um sistema de certificação que tenha não apenas validade e legitimidade perante a lei, mas que seja reconhecido também pelos empregadores?

TS - Nossa experiência revela que os processos de certificação de competências já desenvolvidos no Brasil têm a aceitação do setor produtivo, especialmente porque as escolas de educação profissional no Brasil gozam de respeito e reconhecimento pela sociedade. Não identificamos problemas na aceitação dos certificados emitidos pelos processos de certificação. Resta-nos ampliar essa oferta para cobrir a demanda expressiva de certificação de competências no país. Quanto mais difundida a oferta de certificações, mais aceitação e reconhecimento essa ação terá.

NN - Um dos propósitos do Re-Saber, anunciados pelo Ministério da Educação, é o de simplificar e desburocratizar o processo de certificação profissional. Quais mudanças em relação ao modelo anterior foram implementadas para alcançar esse objetivo, sem comprometer a transparência e a confiabilidade do processo de certificação? 
TS - Houve muitas mudanças em relação ao sistema anterior: simplificação do credenciamento da instituição, ampliação da oferta de certificação por instituições públicas e privadas, ampliação da certificação para toda a oferta de educação profissional, implantação de um programa de capacitação de profissionais para a implantação do Sistema Re-Saber nas escolas técnicas de todo o país, para citar algumas.

NN - O desemprego tem afetado, de modo geral, todas as classes sociais e faixas etárias. No entanto, no Brasil, os jovens em situação de vulnerabilidade social são os mais impactados. A desigualdade nas condições de empregabilidade desses jovens é percebida sobretudo em duas frentes, a da formação profissional e a da inserção no mercado de trabalho. Essa desigualdade é percebida em razão da assimetria de informações acerca das demandas e oportunidades no mercado de trabalho, bem como das competências, habilidades e atitudes requisitadas para cada ocupação. Como a plataforma Monitor de Profissões contribui para reduzir essa assimetria e possibilitar condições mais equitativas para os jovens em condição de vulnerabilidade social?

TS - O Monitor de Profissões, inspirado em experiências internacionais, é uma plataforma pública, acessível a todos, que disponibiliza dados e informações sobre oportunidades de oferta de cursos de educação profissional e tecnológica e acerca do mercado de trabalho. Foram utilizados dados do Inep, da Relação Anual de Informações Sociais (RAIS), do Cadastro Geral de Empregados e Desempregados (CAGED), além de informações dos Catálogos Nacionais de Cursos Técnicos e de Cursos Superiores, da Classificação Brasileira de Ocupações e do Quadro Brasileiro de Qualificações.

Como se sabe, o alinhamento entre demanda e oferta de perfis profissionais é um desafio para a construção das políticas educacionais. As transformações tecnológicas ocorrem em ritmo acelerado, provocando a criação e a extinção de ocupações e influenciando, portanto, os perfis profissionais requeridos pelo mercado. As instituições de ensino, por sua vez, precisam ofertar cursos que estejam em sintonia com esses perfis e promovam uma formação ampla e sólida aos seus egressos.

O fato de o Monitor de Profissões reunir em uma mesma plataforma dados e informações sobre oferta de cursos de educação profissional e tecnológica e oportunidades do mercado de trabalho facilita a identificação das demandas por ocupações, por perfis profissionais e das ofertas de cursos e, consequentemente, a possibilidade de alinhar demanda e oferta de perfis profissionais.

o Monitor de Profissões, portanto, contribui para que as políticas de educação profissional e tecnológica se tornem mais efetivas, ao oferecer subsídios para elevar a empregabilidade dos egressos de seus cursos.

Do ponto de vista individual, o Monitor oferece um conjunto de informações, como ocupações mais requisitadas, média salarial da ocupação, perfis profissionais de cursos, que permitem ao jovem tomar decisões qualificadas em relação às escoIhas de cursos ou de ocupações. 